\title{
Population status of the Critically Endangered waved albatross Phoebastria irrorata, 1999 to 2007
}

\author{
David J. Anderson ${ }^{1, *}$, Kathryn P. Huyvaert ${ }^{2}$, Jill A. Awkerman ${ }^{1,3}$, \\ Carolina B. Proaño ${ }^{4}$, W. Bryan Milstead ${ }^{5}$, Gustavo Jiménez-Uzcátegui ${ }^{5}$, \\ Sebastian Cruz ${ }^{4}$, Jacquelyn K. Grace ${ }^{1}$ \\ ${ }^{1}$ Dept. of Biology, Wake Forest University, Winston-Salem, North Carolina 27109-7325, USA \\ ${ }^{2}$ Dept. of Fish, Wildlife, and Conservation Biology, Colorado State University, Fort Collins, Colorado 80523-1474, USA \\ ${ }^{3}$ National Health and Environmental Effects Research Laboratory, Environmental Protection Agency, \\ Gulf Ecology Division, Gulf Breeze, Florida 32561-5239, USA \\ ${ }^{4}$ Colegio de Ciencias de la Vida, Universidad San Francisco de Quito, Quito, Ecuador \\ ${ }^{5}$ Charles Darwin Research Station, Isla Santa Cruz, Galápagos, Ecuador
}

\begin{abstract}
Understanding the demography of the Critically Endangered waved albatross Phoebastria irrorata is crucial for effective policy responses to recent threats, most notably fishery mortality. Using current vital rates data and a stochastic matrix model, we confirm the conclusion of Awkerman et al. (2006) that the population growth rate $(\lambda)$ was less than 1 in recent years, indicating a shrinking population. Earlier comparisons of recent population size suggested that the breeding population shrunk between 1994 and 2001, but these were based on only 2 counts. A new count in 2007 indicated continued reduction in breeding population size, and the magnitude of the recent reduction was consistent with that projected by our model. New information suggests that plastic ingestion appears to pose a minor threat, if any, to this species, in contrast to the serious problems that it causes in some other albatrosses. Reduction of adult mortality in the coastal fishery appears to be the most effective means to stabilize this threatened species.
\end{abstract}

KEY WORDS: Annual adult survival - Fecundity · Galápagos · Stochastic matrix model · Plastic pollution · Waved albatross

\section{INTRODUCTION}

The waved albatross Phoebastria irrorata was recently uplisted to Critically Endangered on the International Union for Conservation of Nature (IUCN) Red List (IUCN 2008), based in part on strong evidence of reduced annual adult survival and fishery mortality at the species' principal feeding area off the western coast of South America (Awkerman et al. 2006). Weaker evidence concerning trend in population size is consistent with a recent decline (Anderson et al. 2002, Awkerman et al. 2006), but the data are scant, based on only 3 estimates (1970 to 1971,1994 , and 2001). The scarcity of population size estimates motivated an effort in May 2007 to provide a fourth point to inform new policy processes (cf. under the Agreement on the Conservation of
Albatrosses and Petrels) resulting from the 'uplisting'. Here we report the results of this fourth population size estimate. We also update the results of Awkerman et al. (2006), presenting new results concerning annual adult survival over the period 1999 to 2006 and incorporating improved vital rate estimates into population matrix models. Finally, we report the first information concerning plastic ingestion in this species. Plastic ingestion has been implicated in nestling mortality of some other albatross species (Sileo et al. 1990) and has never been evaluated as a risk for waved albatrosses.

Essentially a single-island endemic, almost all waved albatrosses nest on Isla Española (aka Hood Island), Galápagos Islands, Ecuador $\left(1^{\circ} 20^{\prime} \mathrm{S}, 89^{\circ} 40^{\prime} \mathrm{W}\right)$, simplifying the task of estimating population size to some extent. However, the terrain is presently heavily vege- 
tated, in contrast to conditions at the time of the first population size estimate in 1970 and 1971 (Harris 1973) when the vegetation was more open, due to herbivory by feral goats Capra hircus that were eradicated in 1978. By 2001, access to nesting areas in the center of the island was difficult, and we focused then on the large populations at the eastern and western points of the island (Punta Cevallos and Punta Suárez, respectively; Anderson et al. 2002). In 2007, we also focused on these points, using the same field methods as in 2001 to estimate population size.

\section{MATERIALS AND METHODS}

Population size. We counted incubated eggs present at Punta Suárez on May 11 and 12 and at Punta Cevallos on May 12 and 13, 2007 during the seasonal egglaying period to estimate the number of pairs breeding on those days. We augmented those totals using the 'egg loss' and 'egg gain' factors of Anderson et al. (2002), which correct for eggs laid and abandoned before, and those laid after, the dates of the egg count. We determined these correction factors in a subsection of the Punta Cevallos colony (the focal Study Area; see Anderson et al. 2002) in the following way: breaking all abandoned eggs from previous seasons in the Study Area before laying began in 2007; monitoring laying between May 4 and 14, including the new eggs already present on May 4; and returning to the subsection on June 15 to count any new eggs laid after May 14. For a given day of the May 11 to 13 egg count, we divided the number of eggs already lost in the Study Area by the number of eggs incubated in the Study Area on the same day, then multiplied that proportion by the number of eggs counted on the island that day, and added that egg loss factor to the day's island count. We used similar calculations to derive the egg gain factor. Comparison of the partial laying schedule from 2007 with complete laying schedules from other years (Fig. 1) indicated that laying should have finished by June 15 . The Study Area is flat and open, and both incubated and unincubated eggs are detected easily. D. J. A. and K. P. H. were involved in each of the last 3 counts (1994, 2001, 2007), maintaining consistency of methods.

We recorded band numbers of apparent non-breeders daily from May 4 to 14, 2007, and used these records to calculate the size of the non-breeding population that was present over the $10 \mathrm{~d}$ study period within Subcolonies 1 and 2 of Huyvaert \& Anderson (2004), an area much larger than, but encompassing, the focal Study Area described above. The size of this component of the total population was estimated by applying a jackknife estimator and variance and standard error terms described in Burnham \& Overton

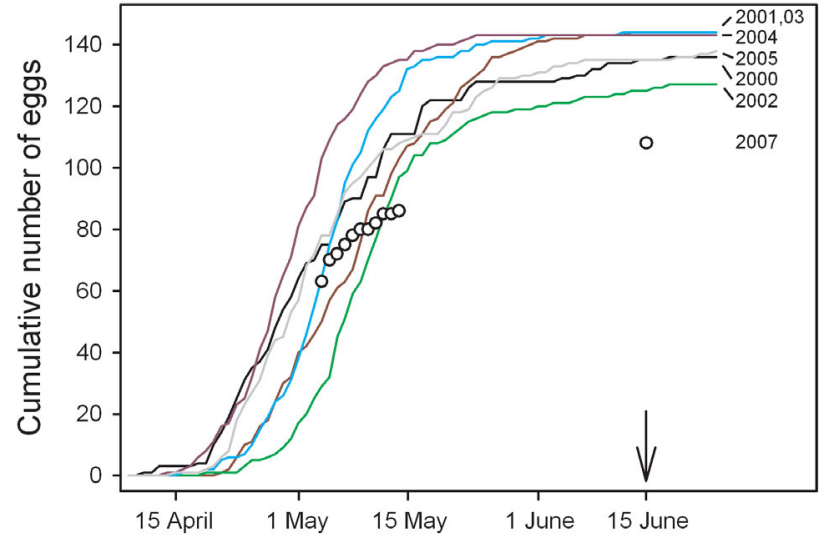

Fig. 1. Phoebastria irrorata. Laying schedules in a subsection of the Punta Cevallos breeding colony, 2000 to 2005, with the partial 2007 schedule shown by circles. The right-most circle shows the total number of eggs laid in 2007 by June 15. Arrow shows the date of the count to determine the value of the 'egg gain factor' (see 'Materials and methods')

(1979) and implemented within Program MARK (White \& Burnham 1999). This research was conducted by permit of the Galápagos National Park Service, as required by Ecuadorian law.

Annual adult survival. As in Awkerman et al. (2006), we used Cormack-Jolly-Seber (CJS) capture-markrecapture methods (Lebreton et al. 1992) implemented in Program MARK (White \& Burnham 1999) to analyze encounter histories of 498 birds banded between 1999 and 2006 to estimate survival and recapture probabilities of adult waved albatrosses within the focal Study Area at Punta Cevallos. Our candidate model set consisted of survival $(\Phi)$ and resight/recapture (p) probability parameters that could: remain constant (.), vary with year $(\mathrm{t})$, vary by sex $(\mathrm{g})$, or include variation from the mild 2002 El Niño Southern Oscillation (ENSO) warm event (E). Given strong evidence for variability in recapture probabilities over time and in survival in response to a mild ENSO warm event (Awkerman et al. 2006), we did not include here several other models that received less support in those previous analyses. We now include new models incorporating additive effects of group (sex) and time (year) on survival and recapture probabilities in light of new evidence of protandry in the colony (Huyvaert et al. 2006). We used Akaike's information criterion (AIC) for model selection and model averaging (Burnham \& Anderson 2002). In practice, we used $\mathrm{QAIC}_{\mathrm{c}}$ a version of AIC adjusted for overdispersion and small sample sizes, incorporating adjustment of the variance inflation factor ( $\hat{\mathrm{c}}$ or 'c-hat') based on the 'median c-hat' approach (=1.73; Cooch \& White 2007). Models with the lowest $\mathrm{QAIC}_{\mathrm{C}}$ values are assumed to better explain variation in the data. 
Population growth rate. Awkerman et al. (2006) produced a periodic stage-based matrix model to estimate lambda ( $\lambda_{i}$ population growth rate) and to evaluate the elasticity of population growth to the matrix elements. The model did not incorporate the sex ratio bias later detected by Awkerman et al. (2007); the female bias reduces population-level estimates of fecundity in this obligately bi-parental species. Here, we reparameterize a simpler model based on only 3 stages using the methods of Awkerman et al. (2006), with 2 modifications. First, the adult sex ratio bias of 0.457 (Awkerman et al. 2007) is incorporated into our calculations of fecundity. Second, the erroneous estimate of annual chick production (0.879) of Awkerman et al. (2006) is replaced with the correct value of juvenile production for a female-based model (0.09), after collapsing the chick and juvenile stages into one stage of longer duration which included all mortality prior to recruitment. The density-independent matrix model developed in the present study is based on a pre-breeding census of juveniles (Age $<5 \mathrm{yr}$ ), subadults that begin returning to the colony but may attempt to breed unsuccessfully for a few years (Age 5 to 8 yr), and breeding adults (Age 9

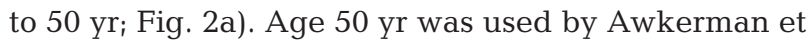
al. (2006) to represent the typical lifespan of waved albatrosses, recognizing that the longest lifespan documented to date (38 yr; Douglas \& Fernández 1997) was limited by the length of the banding program and may well have been longer.

Matrix models were developed for each of $7 \mathrm{yr}$ for which mark-resight data produced adult survival estimates, incorporating these annual estimates for all individuals (Fig. 2b). Because historical juvenile sur-

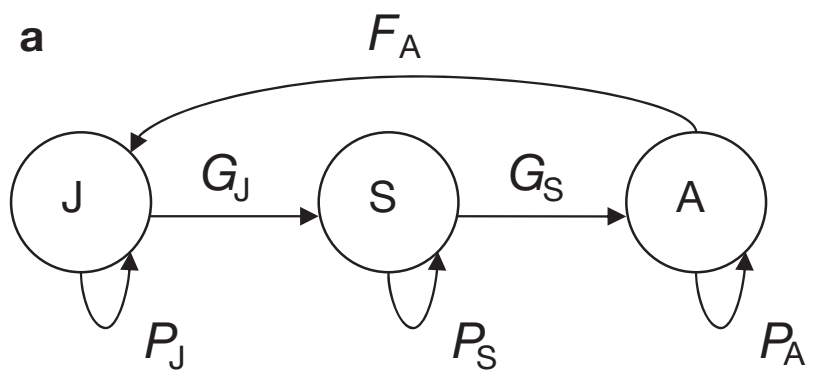

b

$$
A=\left\{\begin{array}{ccc}
P_{\mathrm{J}} & 0 & F_{\mathrm{A}} \\
G_{\mathrm{J}} & P_{\mathrm{S}} & 0 \\
0 & G_{\mathrm{S}} & P_{\mathrm{A}}
\end{array}\right\}
$$

Fig. 2. Phoebastria irrorata. (a) Three-stage life cycle diagram of waved albatross survival $(P)$, fecundity $(F)$, and transition $(G)$ between stages of juveniles $\left(\mathrm{J}_{i}<5 \mathrm{yr}\right)$, subadults $\left(\mathrm{S}_{;} 5\right.$ to $8 \mathrm{yr})$, and adults (A; 9 to $50 \mathrm{yr}$ ) and (b) arrangement of vital rates as matrix elements vival estimates were greater than current adult survival estimates, we used current adult survival estimates for juveniles as well. We suspect that these estimates are optimistic for juveniles, which presumably sustain higher mortality prior to recruitment. In years where the fate of all chicks was not known at the end of the season, we assumed fledging of all nestlings alive at the time our monitoring stopped in our estimates of breeding success. Our data included a single (mild) ENSO warm event over our 7 yr study period, which may be an atypically low frequency of such events over the long term. We showed previously that annual adult survival was reduced markedly during that event (Awkerman et al. 2006). These and other qualifications suggest that our estimates of population growth rate are probably higher than the actual rate.

Matrix elements representing survival estimates $(P)$ are based on a geometric series, which accounts for a decreasing number of individuals by cohort as age increases. Likewise, growth estimates $(G)$ identify the proportion within the oldest cohort of a stage that survive and transition into the next stage (Crouse et al. $1987)$. Fecundity $(F)$ estimates incorporate the proportion of breeders, biased adult sex ratio, and annual fledging success as determined from nest histories collected between 2000 and 2004. As noted above, in cases where the fate of chicks was undetermined at the end of the breeding season under observation, we used the most optimistic estimate of fledging success, which might slightly overestimate the true rate of fecundity. For years in which no estimate of fledging success was available (1999 and 2005), we used the rate typical of recent non-El Niño years (0.23; Awkerman et al. 2006), which was similar to historical estimates of Harris $(0.245 ; 1973)$. To estimate the proportion of living adults that breed (a different parameter from the number of birds present that breed; see subsection 'Population size'), we used the histories (2003 to 2005 seasons) of 271 birds banded as adults in 1999, incorporating this study's mark-recapture estimates of annual adult survival to calculate the predicted number of these birds alive in given years. Juvenile waved albatrosses have returned to the colony as early as Age 2, typically very late in the breeding season (i.e. December), but most birds do not attempt to breed until Age 5 or 6 (Harris 1973), which supports our assumption that all birds banded as adults before early November 1999 would be at least 7 yr old by 2003 and would have had the opportunity to breed in the years 2003 to 2005. Of adults banded in 1999 and expected to be alive in each of the years from 2003 to 2005, the proportion that bred in each year averaged 0.68 (range $=0.66$ to 0.71 ) .

Stochastic $\log$ growth rate, $\log \lambda_{\mathrm{S}}$, for contemporary data was estimated both by Tuljapurkar's approximation and by simulation (Tuljapurkar 1990, Morris \& 
Doak 2002). Estimates of variance were calculated from both 50000 and 20000 simulated growth increments chosen with equal probability from the 7 annual matrices (1999 to 2005). We report elasticities of the mean matrix, calculated from the 7 annual matrices (Caswell 2001).

For comparison with these contemporary estimates of vital rates with those from historical data, a deterministic stage-based matrix model was also constructed for waved albatrosses using vital rates measured by Harris (1973) in the 1960s. Elasticity values of this matrix were calculated to identify matrix elements to which population growth is most sensitive. We use a deterministic model for these historical data because they do not permit a parallel stochastic approach. As a result, our interpretation of the results is essentially qualitative.

Plastic ingestion. In November 2007, we dissected the proventriculus of each of 40 dead waved albatross nestlings, and 3 additional birds that were either fledglings or adults, representing all dead albatrosses that we could find in Subcolonies 1 to 4 of Huyvaert \& Anderson (2004) and areas between these subcolonies. Two of the nestlings died $2 \mathrm{~d}$ prior to examination. All other birds had been dead for some months and perhaps years. Most of the 40 nestlings were small and appeared to have died between Age 10 and $40 \mathrm{~d}$.

\section{RESULTS}

\section{Population size}

The numbers of incubated eggs during our counts totaled 1137 at Punta Suárez and 3268 at Punta Cevallos. We applied the egg loss and egg gain factors for May 11, 12, and 13 (egg loss: 0.11, 0.094, and 0.11; egg gain: $0.27,0.26$, and 0.26 , respectively) to obtain estimates of the total number of eggs laid at Punta Suárez (1569) and Punta Cevallos (4476). These estimates showed continued decline in the breeding population size at both sites (Fig. 3a), although the decline at Punta Cevallos was marginal. No estimate of error is possible from these data. The proportional decline between 1994 and 2001 was essentially identical at the 2 sites, and the Punta Suárez subpopulation continued on this trajectory from 2001 to 2007, while the Punta Cevallos subpopulation declined little (Fig. 3b). The combined estimates of breeding populations of the 2 sites in 2007 (totaling 6045 pairs = 12090 ind.) was $88.1 \%$ of that in 2001 (6857 pairs; Anderson et al. 2002).

The size of the non-breeding portion of the population present at Punta Cevallos from 4 to 14 May was 1073 ( $\pm 93.35 \mathrm{SE}$ ) with an approximate 95\% confidence interval of 996 to 1450 ind. Using this estimate

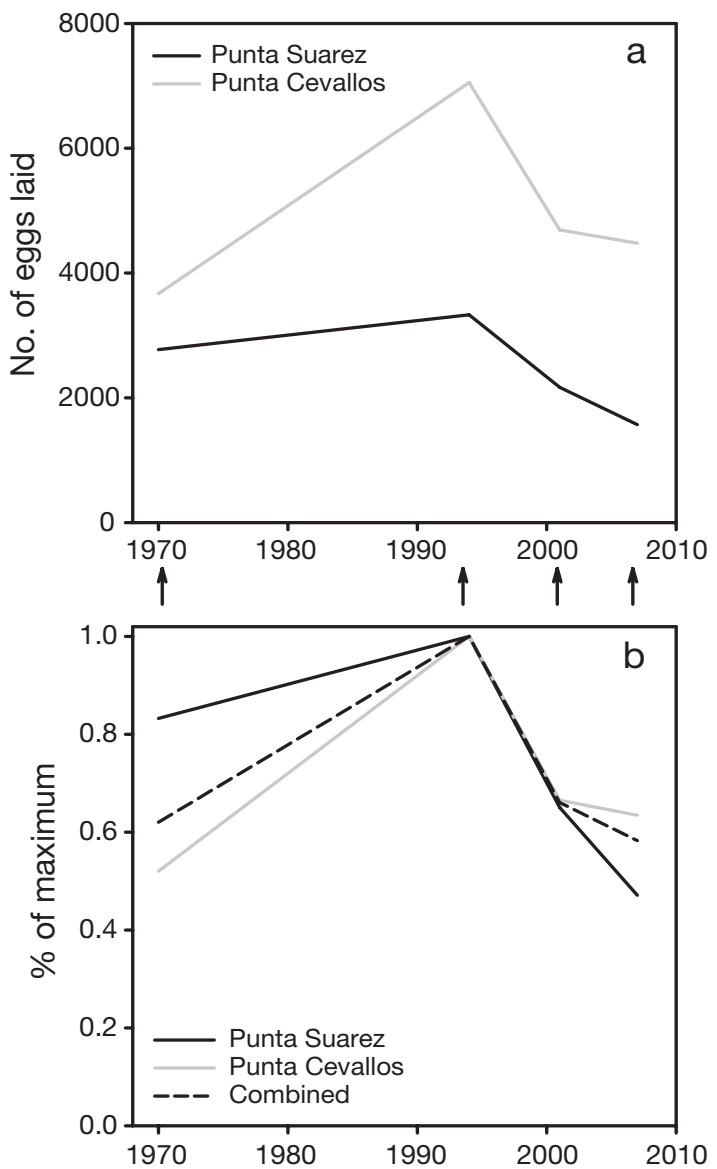

Fig. 3. Phoebastria irrorata. Trend in size of the breeding population of waved albatrosses at 2 principal breeding sites on Isla Española, Galápagos. (a) Estimate of number of eggs laid in each breeding season corrected for egg loss and gain (see 'Materials and methods'). (b) Number of eggs laid per season scaled to the maximum number observed. Arrows in (a) indicate timing of the 4 population counts

for non-breeders and the estimate of the number of breeders corrected for egg losses and gains within the same geographic area, the ratio of non-breeders (1073) to breeders (corrected no. of eggs $\times 2=1914$ ) was 0.56 . The number of non-breeders present in the combined Punta Suárez and Punta Cevallos population was thus estimated as $6045 \times 0.56=3385$, and the sum of breeders and non-breeders present in these areas in 2007 was $6045 \times 2+3385=15475$.

\section{Annual adult survival}

Our top-ranking model allowed recapture/resight probability to vary by year and held apparent survival constant across years except during the mild ENSO warm event in 2003. Other high-ranking models $\left(\Delta \mathrm{QAIC}_{\mathrm{C}}<4\right)$ included additive variation by sex for 
both recapture and apparent survival probabilities (Table 1). Models incorporating only variation by group in recapture probabilities received no support.

For both sexes, model averaged estimates of apparent annual survival varied from 0.930 in 2002 to 0.859 in the following year when mild ENSO conditions prevailed (Fig. 4). Model averaged estimates of apparent survival for 2005 and 2006, for which we have new data, were 0.921 and 0.928 , respectively.

\section{Population growth rate}

A deterministic matrix model parameterized with historical vital rate estimates (Harris 1973) produced a population growth rate $(\lambda)$ of 0.9969 during the $1960 \mathrm{~s}$, indicating a virtually stable population size. Population growth rate in the 1960s was most sensitive to changes in adult survival (elasticity $=0.69$ ). The matrices used to derive these $\lambda$ and elasticity values are provided in Appendix 1.

Annual estimates of productivity for 1999 to 2005 varied from 0.08 in 2003 to 0.37 in 2001 (Table 2). Using these rates in estimates of fecundity, a stochastic matrix model parameterized with data from 1999 to 2006 estimated $\lambda$ as 0.9615 (Tuljapurkar's log stochastic growth approximation method), and also 0.9615 using a simulation approach $(95 \% \mathrm{CI}=0.9611,0.9618)$. Reducing the number of simulated years to 20000 slightly increased the confidence limits (0.9609, 0.9620). Elasticity values for the mean matrix of contemporary matrices were also highest for the matrix element representing adult survival (elasticity $=0.69$ ).

Table 1. Phoebastria irrorata. Set of candidate models of apparent survival $(\Phi)$ and recapture/resight (p) probabilities incorporating variation over years (t), by sex (g), and after a mild ENSO event (E) for adult waved albatrosses. For an explanation of $\mathrm{QAIC}_{\mathrm{C}}$ see 'Materials and methods; Annual adult survival'

\begin{tabular}{|lccccc|}
\hline Model & QAIC $_{\mathrm{C}}$ & $\Delta$ QAIC $_{\mathrm{C}}$ & $\begin{array}{c}\text { QAIC }_{\mathrm{C}} \\
\text { weights }\end{array}$ & $\begin{array}{c}\text { Model } \\
\text { likelihood }\end{array}$ & $\begin{array}{c}\text { Number of } \\
\text { parameters }\end{array}$ \\
\hline$\Phi(\mathrm{E}) \mathrm{p}(\mathrm{t})$ & 1823.74 & 0.00 & 0.41 & 1.00 & 10 \\
$\Phi(\mathrm{E}) \mathrm{p}(\mathrm{g}+\mathrm{t})$ & 1825.14 & 1.40 & 0.20 & 0.50 & 11 \\
$\Phi(\mathrm{g}+\mathrm{E}) \mathrm{p}(\mathrm{t})$ & 1825.76 & 2.02 & 0.15 & 0.36 & 11 \\
$\Phi(\mathrm{g}+\mathrm{E}) \mathrm{p}(\mathrm{g}+\mathrm{t})$ & 1827.15 & 3.41 & 0.07 & 0.18 & 12 \\
$\Phi(\mathrm{t}) \mathrm{p}(\mathrm{t})$ & 1827.30 & 3.56 & 0.07 & 0.17 & 15 \\
$\Phi(\mathrm{t}) \mathrm{p}(\mathrm{g}+\mathrm{t})$ & 1828.45 & 4.71 & 0.04 & 0.10 & 16 \\
$\Phi(\mathrm{g}+\mathrm{t}) \mathrm{p}(\mathrm{t})$ & 1829.28 & 5.53 & 0.03 & 0.06 & 16 \\
$\Phi(\mathrm{g}+\mathrm{t}) \mathrm{p}(\mathrm{g}+\mathrm{t})$ & 1830.41 & 6.67 & 0.01 & 0.04 & 17 \\
$\Phi(\mathrm{g}) \mathrm{p}(\mathrm{t})$ & 1830.57 & 6.83 & 0.01 & 0.03 & 10 \\
$\Phi(\mathrm{g}) \mathrm{p}(\mathrm{g}+\mathrm{t})$ & 1831.92 & 8.18 & 0.01 & 0.02 & 11 \\
$\Phi(\mathrm{t}) \mathrm{p}(\mathrm{g})$ & 1842.94 & 19.20 & 0.00 & 0.00 & 10 \\
$\Phi(\mathrm{g}+\mathrm{t}) \mathrm{p}(\mathrm{g})$ & 1844.86 & 21.12 & 0.00 & 0.00 & 11 \\
$\Phi(\mathrm{E}) \mathrm{p}(\mathrm{g})$ & 1846.37 & 22.63 & 0.00 & 0.00 & 4 \\
$\Phi(\mathrm{g}+\mathrm{E}) \mathrm{p}(\mathrm{g})$ & 1848.37 & 24.63 & 0.00 & 0.00 & 5 \\
$\Phi(\mathrm{g}) \mathrm{p}(\mathrm{g})$ & 1849.19 & 25.44 & 0.00 & 0.00 & 4 \\
\hline
\end{tabular}

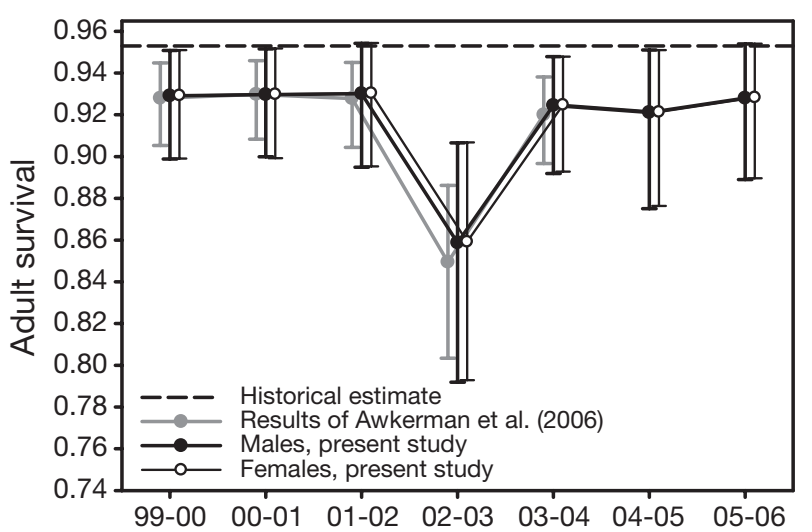

Fig. 4. Phoebastria irrorata. Parameter estimates and 95\% confidence limits of annual adult survival for adult waved albatrosses based on model averaging of all candidate models. Approximations of the lower binomial $95 \%$ confidence limit of the historical estimate (Harris 1973) range from 0.940 to 0.941 (Awkerman et al. 2006) and do not include any of our estimates. Results from the current analysis are shown separately for males and females, given the weak support for a sex difference (see Table 1). Comparable results from Awkerman et al. (2006) for the 2 sexes combined are shown for reference

\section{Plastic ingestion}

Only $3(7.0 \%)$ birds dissected in November 2007 contained proventricular plastic. In one large chick that died accidentally on October 30 , we found a small piece of stiff material, $8 \times 18 \mathrm{~mm}$, that appeared to be plastic. Another dead nestling contained a smaller piece of material that appeared to be of anthropogenic origin, possibly plastic. Another nestling contained a piece of plastic that may have been the wrapper for a piece of hard candy. No other birds contained plastic. We observed, but did not quantify, the presence of pebbles whose appearance indicated local origin, and of the seeds of a local terrestrial plant Cordia lutea. Eggshell pieces were also found in some birds.

\section{DISCUSSION}

\section{Population size}

Our estimate of the breeding population size of the Punta Suárez and Punta Cevallos colonies continued the decline (Fig. 3) suggested by the results of the 2001 count (Anderson et al. 2002). Although our ability to make quantitative conclusions is limited by 
Table 2. Phoebastria irrorata. Estimates of apparent survival (determined by mark-recapture analyses) and productivity (fledgling per breeding female) for 1960s and 1999 to 2006

\begin{tabular}{|lcc|}
\hline Year & $\begin{array}{c}\text { Adult survival } \\
\text { probability }\end{array}$ & Productivity \\
\hline 1960 s & 0.953 & 0.254 \\
1999 to 2000 & 0.929 & 0.230 \\
2000 to 2001 & 0.930 & 0.304 \\
2001 to 2002 & 0.930 & 0.369 \\
2002 to 2003 & 0.859 & 0.114 \\
2003 to 2004 & 0.925 & 0.079 \\
2004 to 2005 & 0.921 & 0.278 \\
2005 to 2006 & 0.928 & 0.230 \\
\hline
\end{tabular}

the lack of information regarding the error of the population size estimates, a qualitative conclusion seems to be warranted: breeding population size has declined since 1994, and possibly also since 2001. The uplisting of the species to Critically Endangered in 2007 will make new resources available to upgrade the techniques used to estimate population size, a process that has already started, involving a working group comprising the Galápagos National Park Service, the Charles Darwin Research Station, and our group.

The estimate for the combined (both Punta Suárez and Punta Cevallos) breeder/non-breeder population in 2007 was 15475 ind. A comparable figure for 2001 (6857 pairs $\times 2=13714$ breeders; 0.37 non-breeders/ pair $\times 6857$ pairs $=2537$ non-breeders; Anderson et al . 2002 ) is 16251 . Thus, the total adult population present during the 2 surveys was similar and lower than in 1994, and the reduction in breeding population size between 2001 and 2007 was approximately balanced by an increase in the non-breeder component of the population in $2007(3385 / 15475=0.219)$ compared to that of $2001(2537 / 16251=0.156)$. These data raise a new conservation concern: that a reduction in breeding population size may be due not only to excess mortality at sea (Awkerman et al. 2006), but possibly also to factors that limit participation of living adults in breeding. Improved monitoring techniques should be designed to evaluate this possibility more completely than is possible with our simple count data.

\section{Annual adult survival and population growth rate}

Our estimates of annual adult survival were similar to those of Awkerman et al. (2006), below the historical estimate of Harris (1973), and consistently between 0.92 and 0.93 except during the mild ENSO warm event (Fig. 4). Our population models indicate that this reduction in adult survival since 1970 is sufficient to cause population decline. The population growth rate using historical vital rate estimates is virtually 1 , indicating a stable population in the 1960s. In contrast, our contemporary estimate of $\lambda(0.9615)$ indicates a shrinking population, and the confidence limits of this stochastic growth rate estimate do not approach stable population growth. If this growth rate was characteristic of the population from 1994 to 2007, the population should shrink by $40 \%$ (= 1 $0.9615^{13}$ ) in this time interval. This prediction approximates the actual reduction of $42 \%$ that our count data suggest for the breeding population size over this 13 yr period (Fig. 3b). While the assumption of a constant $\lambda$ is unrealistic because of environmental variability, this exercise has nonetheless some value in suggesting an internally consistent picture painted by the different datasets over time.

For several reasons, we suspect that our estimate of the current population growth rate is inflated. Some recent fecundity and juvenile survival estimates were uncertain, and we chose to err on the optimistic side. The age distribution of adults banded in 1999 was unknown, so the banded population of breeders may include some young, unsuccessful breeders, representing the second life stage but included in our modeling as the third (reproductive) stage, thus inflating the fecundity estimate. Juvenile survival is almost certainly overestimated. Also, in our models, juvenile survival was not permitted to vary independently of adult survival, so the modeling outcome does not reflect the actual covariance of juvenile survival with other vital rates. Given these qualifications, our estimate of population growth rate should be considered a maximum value. Error associated with environmental stochasticity is also possible. The span of years analyzed does not include any years of complete breeding failure, as occurs during strong ENSO warm events (Rechten 1985), and also lacks possible years of very high success and/or survival. Therefore, our calculation of the specific value of $\lambda$ should be interpreted with some reserve until we fully understand the effect of environmental stochasticity on population dynamics (Morris \& Doak 2002).

Our assumption regarding length of time passed as a breeding adult could also inflate the estimate of population growth rate. Insufficient age-specific data prevent inclusion of a fourth, senescent stage in our matrix model, in which adults with advanced age could show low reproductive success and/or survival. Because of the relative importance of adult survival to this population's demography, we repeated our analyses assuming a lifespan of $38 \mathrm{yr}$ (the age of the oldest bird recorded to date; Douglas \& Fernández 1997), reducing the period of the breeding adult stage by $12 \mathrm{yr}$. Stochastic population growth rate fell under these conditions (approximation $=0.9582$, simulation $=0.9583$, 
confidence limits, $\mathrm{CL}=0.9580$ to 0.9587 ). The historical population growth rate was also reduced (0.9916), and remained much more sensitive to changes in adult survival than to other matrix elements (elasticity $=0.68$ ).

\section{Plastic ingestion}

Materials of anthropogenic origin have been found in the digestive tracts of a number of albatross species (Fry et al. 1987, Ryan 1988, Petry et al. 2007), and have been implicated in the deaths of nestlings (Sileo et al. 1990). Because the incidence of plastic ingestion shows substantial temporal variation in other seabird species (Day et al. 1985, Furness 1985a,b), further study is required to conclusively evaluate the exposure of nestling waved albatrosses to marine plastic. However, our data indicate that plastic ingestion is relatively rare in this species. The plastic that is ingested is small in number and size, and most nestling mortality appears to be unrelated to plastic ingestion. The results of our elasticity analysis indicate that such infrequent effects of plastic ingestion would have a relatively small impact on population dynamics. Mortality of adults in the artesanal Peruvian fishery (Awkerman et al. 2006) remains the most compelling explanation for the population dynamics of this species in recent years.

Acknowledgements. We thank the Galápagos National Park Service for permission to work in the Park; the Charles Darwin Research Station and TAME Airline for logistical support; the Swiss Friends of Galápagos and the Galápagos Conservancy for research funding; our many competent assistants for their work in producing the resight database; P. Lukacs and P. Doherty for guidance during modeling efforts; A. Guézou for identification of seeds in proventriculi; and 2 anonymous reviewers for comments on an earlier draft. This material is based upon work supported by the National Science Foundation under Grant Nos. DEB 98-06606 and DEB 0235818 to DJA.

\section{LITERATURE CITED}

Anderson DJ, Huyvaert KP, Apanius V, Townsend $\mathrm{H}$ and others (2002) Waved albatross population size and trends. Mar Ornithol 30:63-69

> Awkerman JA, Huyvaert KP, Mangel J, Alfaro Shigueto J, Anderson DJ (2006) Incidental and intentional catch threatens Galápagos waved albatross. Biol Conserv 133: $483-489$

Awkerman JA, Westbrock MA, Huyvaert KP, Anderson DJ (2007) Female-biased sex ratio arises after parental care in sexually dimorphic waved albatross. Auk 124:1336-1346

Burnham KP, Anderson DR (2002) Model selection and inference: a practical information-theoretic approach. Springer-Verlag, New York

Burnham KP, Overton WS (1979) Robust estimation of popula- tion size when capture probabilities vary among animals. Ecology 60:927-936

Caswell H (2001) Matrix population models: construction, analysis, and interpretation, 2nd edn. Sinauer Associates, Sunderland, MA

Cooch ED, White GC (2007) Program MARK 'A gentle introduction,' 6th edn. Available at: www.phidot.org/ software/mark/docs/book/ (accessed 30 Nov 2007)

> Crouse DT, Crowder LB, Caswell H (1987) A stage-based population model for loggerhead sea turtles and implications for conservation. Ecology 68:1412-1423

Day RH, Wehle DHS, Coleman F (1985) Ingestion of plastic pollutants by marine birds. In: Shomura RS, Yoshida HO (eds) Proceedings of the workshop on the fate and impact of marine debris, 26-29 November 1984, Honolulu, HI. US Dept. of Commerce, NOAA Tech Memo. NMFS-SWFS54:344-386

Douglas HD, Fernández P (1997) A longevity record for the waved albatross. J Field Ornithol 68:224-227

> Fry DM, Fefer SI, Sileo L (1987) Ingestion of plastic debris by laysan albatrosses and wedge-tailed shearwaters in the Hawaiian Islands. Mar Pollut Bull 18:339-343

Furness RW (1985a) Ingestion of plastic particles by seabirds at Gough Island, South Atlantic Ocean. Environ Pollut Ser A Ecol Biol 38:261-272

Furness RW (1985b) Plastic particle pollution: accumulation by procellariiform seabirds at Scottish colonies. Mar Pollut Bull 16:103-106

Harris MP (1973) The biology of the waved albatross Diomedea irrorata of Hood Island, Galápagos. Ibis 115:483-510

> Huyvaert KP, Anderson DJ (2004) Limited dispersal in the Nazca booby. J Avian Biol 35:46-53

> Huyvaert KP, Anderson DJ, Parker PG (2006) Mate opportunity hypothesis and extrapair paternity in waved albatrosses (Phoebastria irrorata). Auk 123:524-536

IUCN (2008) IUCN Red List of Threatened Species, IUCN. Available at: www.iucnredlist.org. Last update on 10 January 08 (accessed 11 Jan 2008)

Lebreton JD, Burnham KP, Clobert J, Anderson DR (1992) Modeling survival and testing biological hypotheses using marked animals: a unified approach with case studies. Ecol Monogr 62:67-118

Morris WF, Doak DF (2002) Quantitative conservation biology: theory and practice of population viability analysis. Sinauer Associates, Sunderland, MA

> Petry MV, Fonseca VSD, Scherer AL (2007) Analysis of stomach contents from the black-browed albatross, Thalassarche melanophris, on the Coast of Rio Grande do Sul, Southern Brazil. Polar Biol 30:321-325

Rechten C (1985) The waved albatross in 1983-El Niño leads to complete breeding failure. In: Robinson $G_{\text {, del }}$ Pino EM (eds) El Niño in the Galápagos Islands: the 19821983 event. Charles Darwin Foundation for the Galápagos Islands, Quito, Ecuador, p 227-238

Ryan PG (1988) Intraspecific variation in plastic ingestion by seabirds and the flux of plastic through seabird populations. Condor 90:446-452

Sileo L, Sievert PR, Samuel MD (1990) Causes of mortality of albatross chicks at Midway Atoll. J Wildl Dis 26:329-338

Tuljapurkar S (1990) Population dynamics in variable environments. Springer-Verlag, New York

White GC, Burnham KP (1999) Program MARK: survival estimation from populations of marked animals. Bird Study 46(Suppl):120-138 
Appendix 1. Deterministic stage-based matrices for historical vital rates $\left(A_{H}\right)$ and elasticity results $\left(E_{H}\right)$ with recent annual matrices used to determine stochastic growth rate $\left(\mathrm{A}_{99}\right.$ to $\left.\mathrm{A}_{05}\right)$, where subscripts represent year of investigation

$\begin{array}{rlrl}\mathrm{A}_{\mathrm{H}} & =\left\{\begin{array}{ccc}0.775 & 0 & 0.079 \\ 0.165 & 0.65 & 0 \\ 0 & 0.303 & 0.946\end{array}\right\} & \mathrm{E}_{\mathrm{H}}=\left\{\begin{array}{ccc}0.13 & 0 & 0.037 \\ 0.037 & 0.07 & 0 \\ 0 & 0.037 & 0.689\end{array}\right\} \\ \mathrm{A}_{99}=\left\{\begin{array}{ccc}0.769 & 0 & 0.071 \\ 0.159 & 0.641 & 0 \\ 0 & 0.286 & 0.924\end{array}\right\} & \mathrm{A}_{03}=\left\{\begin{array}{ccc}0.735 & 0 & 0.024 \\ 0.124 & 0.615 & 0 \\ 0 & 0.244 & 0.858\end{array}\right\} \\ \mathrm{A}_{00}=\left\{\begin{array}{ccc}0.769 & 0 & 0.094 \\ 0.159 & 0.641 & 0 \\ 0 & 0.286 & 0.924\end{array}\right\} & \mathrm{A}_{04}=\left\{\begin{array}{ccc}0.769 & 0 & 0.071 \\ 0.159 & 0.641 & 0 \\ 0 & 0.286 & 0.924\end{array}\right\} \\ \mathrm{A}_{01}=\left\{\begin{array}{ccc}0.714 \\ 0.769 & 0 & 0.114 \\ 0.159 & 0.641 & 0 \\ 0 & 0.286 & 0.924\end{array}\right\} & \mathrm{A}_{05}=\left\{\begin{array}{ccc}0.769 & 0 & 0.071 \\ 0.159 & 0.641 & 0 \\ 0 & 0.286 & 0.924\end{array}\right\} \\ \mathrm{A}_{02}=\left\{\begin{array}{ccc}0.769 & 0 & 0.035 \\ 0.159 & 0.641 & 0 \\ 0 & 0.286 & 0.924\end{array}\right\} & & & \end{array}$

Editorial responsibility: Rory Wilson,

Swansea, UK
Submitted: January 18, 2008; Accepted: March 4, 2008 Proofs received from author(s): May 18, 2008 